\title{
STUDY ON VESSEL MOTION CONTROL WITH TOWING ROPES AND DAMPERS FOR BERTHING
}

\author{
TAE-WAN KIM ${ }^{1}$, DONG-HUN LEE ${ }^{1}$, JIN-HO SUH $^{1}$, YONG-WOON CHOI $^{2}$ \& YOUNG-BOK KIM ${ }^{1}$ \\ ${ }^{1}$ Department of Mechanical System Engineering, Pukyong National University of Busan, South Korea \\ ${ }^{2}$ School of Engineering, Soka University of Hachioji, Japan
}

\begin{abstract}
The problem of manoeuvring vessels within harbour areas is generating considerable interest in terms of marine cybernetics. The vessel is operated by the pilot and moves at low or zero speeds in shallow water areas. In this case, the vessel is usually assisted by the cooperation of thrusters, main propulsion systems, tugboats and pilots, etc. In this paper we suggest a new vessel berthing technique using dampers and winches as a solution for complex and dangerous berthing work. In the proposed berthing method, we design the controller to counteract the waves and other effects for guaranteeing safety during the berthing process. Experiments are also conducted to verify the proposed vessel berthing method and the effectiveness of the designed control system in which unpredictable external force is applied. Finally, the experiment results show that the vessel could approach the defined position in time with effective control action made from designed controller.
\end{abstract}

Keywords: vessel, tension, harbour, berthing system, winch, damper.

\section{INTRODUCTION}

Vessel berthing is widely considered as the most complicated process in the marine control and automation field [1]-[3]. A reason is that the hydrodynamic of the vessel considerably changes, and its controllability is greatly cut down when the vessel moves from deep to shallow water. Furthermore, by only manipulating the main propellers and thrusters, it is very easy for dangerous collisions to appear between the manoeuvred vessel and the moored ones because of unpredictable vessel motion [4].

Various approaches have been tried to make some solutions about this problem. Bui et al. [5], [6] and Bui and Kim [7] conducted automatic ship berthing by using bow and stern thrusters. The authors introduced a steering motion model of a vessel and identified all of the model parameters. An observer based optimal controller was designed to cope with the uncertain ship dynamics to obtain desirable control performance by estimating system states. This approach seems to be a useful method, but the reduced actuator controllability under low-speed conditions has not fully been resolved. In 1994, Hasegawa and Fukutomi [8] suggested an artificial neural network control strategy for automatic vessel berthing.

However, the conventional methods proposed in this time are kinds of automatic manoeuvring technologies or methods which could not give any useful solutions for completing berthing work.

Therefore, the authors propose a new method to complete the final berthing process with preserving working safety. The proposed system configuration is illustrated in Fig. 1. As shown in Fig. 1, the two damper cylinders and two winch systems are prepared for controlling ship motion. Pulling by winch with rope and pushing with damper the vessel, we can move the vessel to the final position more safely. It means that the complicate berthing work could be completed by controlling winches and dampers with designed control system without any supporting system. The effectiveness and usefulness of proposed method are clearly presented by experiment results. 


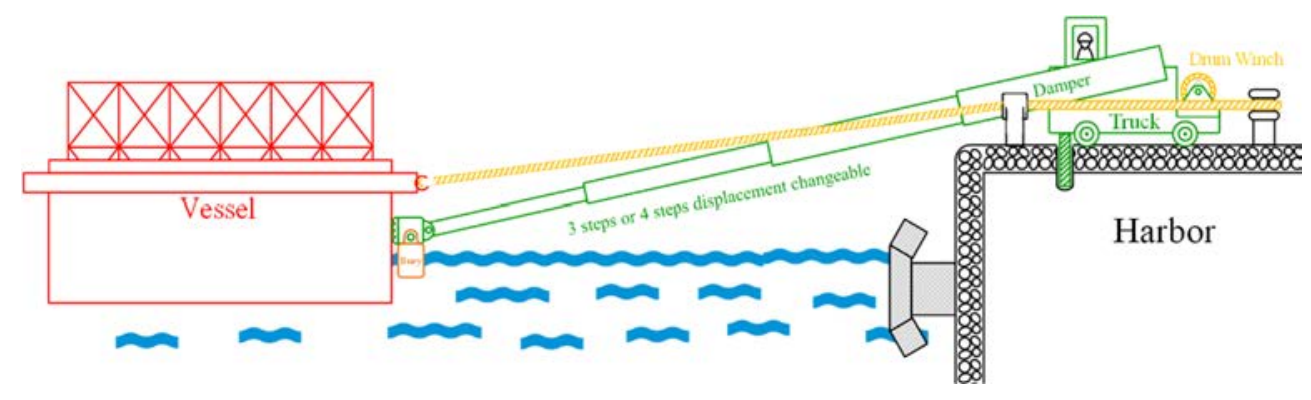

Figure 1: Schematic drawing of the proposed berthing system.

\section{SYSTEM DESCRIPTION AND MODELING}

The system proposed and intended for experiment is shown in Fig. 2. The authors use a vessel model to execute the berthing experiment, where two pairs of motor and pneumatic cylinder are installed in the harbour side.

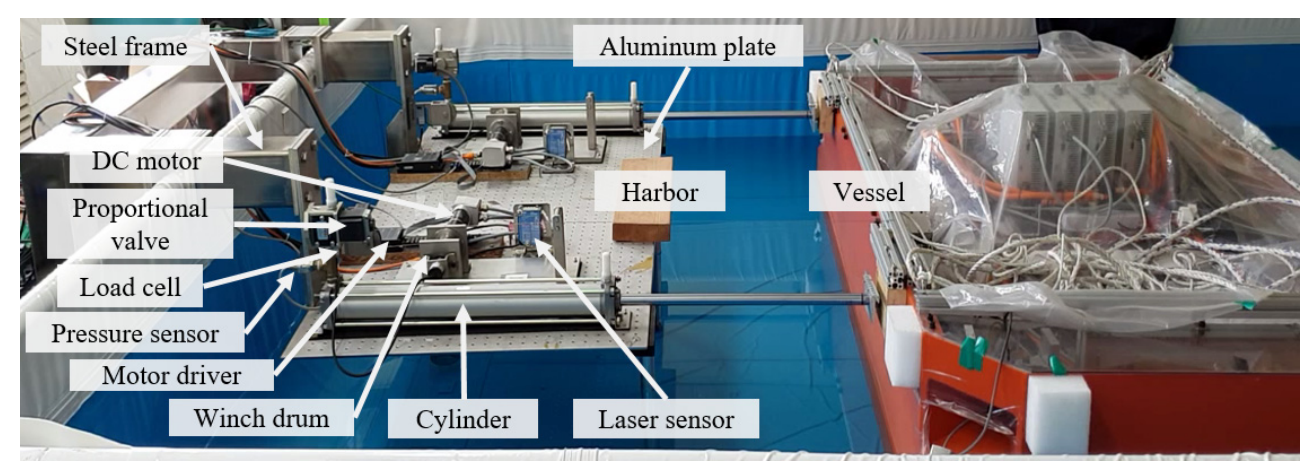

Figure 2: Schematic drawing for the berthing system.

The proposed idea and system configuration are initialized by considering final berthing condition. The most complicate area (or distance) for berthing may be confined in $10 \mathrm{~m}$ from ship to quay side. In this area, generally, the tugboats and pilot assistance are needed to occupy safe working process. The object of this study is to show an easier and safer method than conventional technologies. In the proposed method, any additional assistance system such as tugboat or pilot is not necessary except damper and winch systems installed on the land side. The possibility of the proposed method is presented by following experiment.

As previously mentioned, two pairs of winch and damper cylinder are prepared for controlling ship motion. For starting berthing work, at first, the ends of dampers are attached and the winch ropes are connected to the vessel simultaneously. After that, the berthing process is started by controlling pulling and pushing forces made from actuators (see Fig. 5). It means that the desirable control performance and safe berthing work can be achieved by controlling winch and damper systems properly and effectively. 


\subsection{System modelling}

Based on the preparation of experiment apparatus, the authors performed the system identification process to analysis the dynamic characteristics of vessel berthing system.

At first, in order to obtain the transfer function of winch system, $10 \mathrm{~V}$ electric power (shown in Fig. 3(a)) was applied to the winch system such that the rope tension force was obtained as shown in Fig. 3(b). In this figure, the dotted line is tension force get from experiment and the solid line is calculated tension force obtained from a transfer function of winch system.

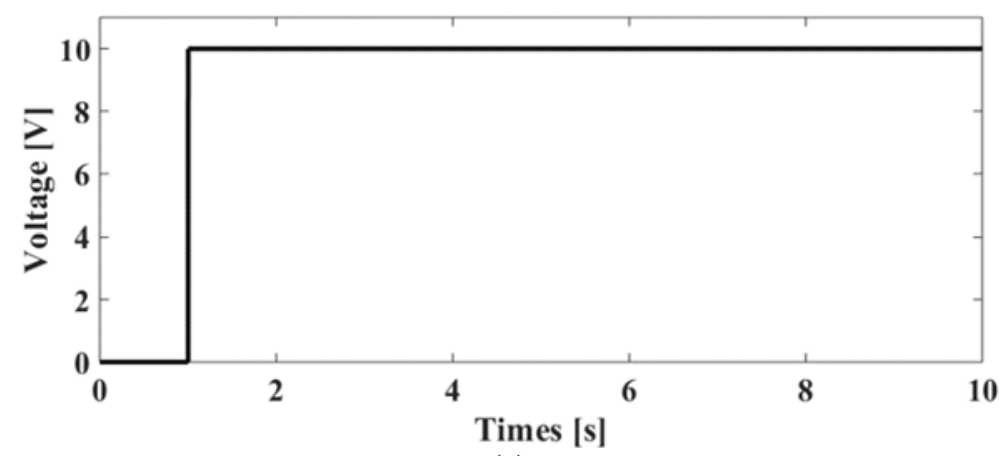

(a)

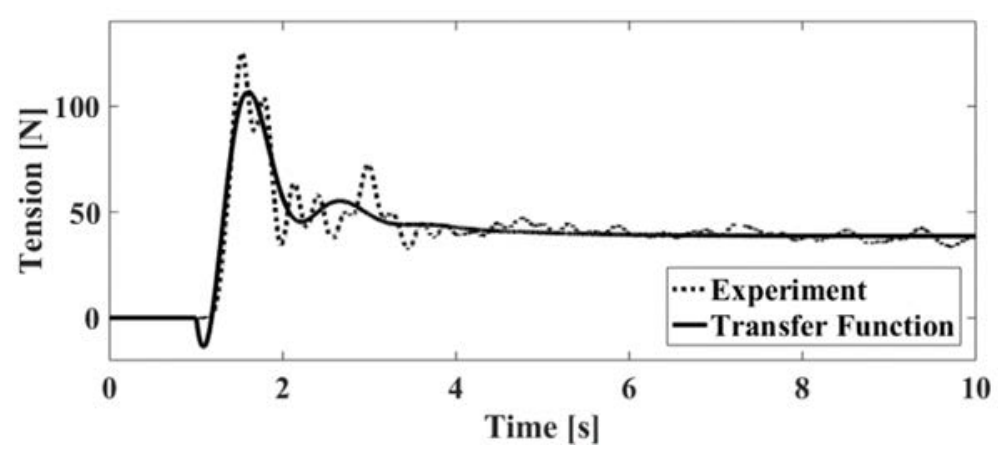

(b)

Figure 3: System identification result. (a) Input voltage; and (b) Output tension.

The transfer function of winch system which shows the relation of the input power $V(s)$ and the rope tension force $T(s)$ is presented as follows:

$$
G(s)=\frac{T(s)}{V(s)}=\frac{-34.72 s^{2}+296.3 s+125.1}{s^{3}+4.75 s^{2}+39.77 s+32.4} .
$$

We may provide many types of berthing techniques and methods using the proposed system configuration.

In the proposed berthing system, two dampers and two winches are provided and controlled to achieve the given objective. 
Here, the authors introduce a considerable simple berthing strategy. It is called a semiautomatic berthing method or technique. In this method, the dampers are manually controlled. On the other hand, the winches are automatically controlled such that the rope tension forces are kept in the defined values.

For example, if the damper control valves are closed, the winches rotate and pull the vessel until the tension forces approach to the target values. It means that the vessel motion or position depends on the expended length of damper cylinder under the appropriately defined rope tension. For accomplishing full-automatic berthing system, two actuator system should be actively controlled. However, the semi-automatic berthing method is most friendly one for real working condition and environment. Based on this idea, the authors tried berthing experiment in several times such that the results will be shown in the next section.

\section{EXPERIMENT}

\subsection{Experimental apparatus}

In order to evaluate the usefulness of designed control system, the experimental apparatus is set up and tested in the water basin. The experiment was performed in water basin using a vessel model (weight: $215 \mathrm{~kg}$, length: $2 \mathrm{~m}$, width: $1 \mathrm{~m}$ ).

The vessel motions are measured and controlled by data acquisition system PCI-6229 (NI) with LabVIEW software.

A pair of winch and damper system is installed on the harbour side. The distance from the vessel to the harbour is measured by the Laser sensor mounted on the plate, the rope tension is measured by Load cell sensor and the cylinder pressure is measured by pressure sensor. All apparatus used for experiment are represented in Fig. 2.

\subsection{Controller design}

We design a controller based on sliding mode control scheme in order to keep the desired rope tension. Especially, the super-twisting algorithm is introduced for designing sliding mode controller. The configuration of designed feedback control system is illustrated in Fig. 4. Then, the typical form of a sliding surface is given as follows:

$$
\sigma=\ddot{e}+G_{1} \dot{e}+G_{2} e
$$

where $e$ is tracking error and $G_{1}=20.67, G_{2}=4.01, \lambda=0.75, k=6.2$.

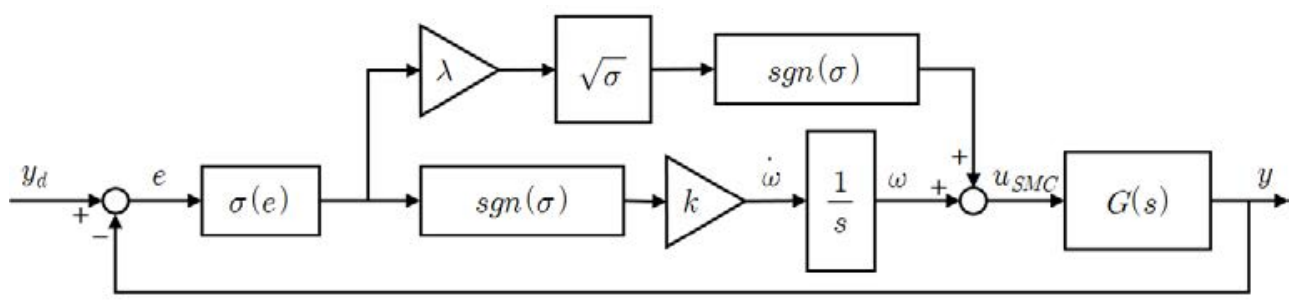

Figure 4: Block diagram for sliding mode control system with super-twisting algorithm. 


\subsection{Experiment results}

The objectives of this study are keeping the target tension of rope and moving the vessel to the desired position simultaneously. Especially, the target rope tension should remain in the defined value throughout entire berthing process.

The authors performed experiment by applying the designed controller. The experiment scenario is illustrated in Fig. 5.

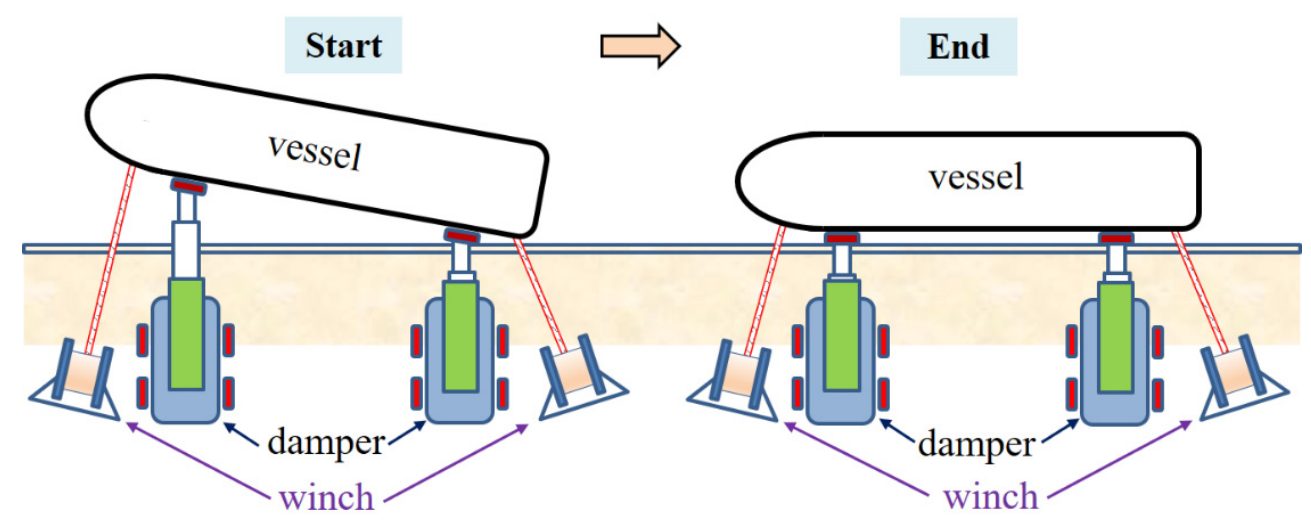

Figure 5: Experiment scenario.

In this study, the target tension was set to $120 \mathrm{~N}$ which is shown as the red dotted line in Fig. 6(b).

In Fig. 6(a) shows vessel position during moving to the final position. While the vessel is approaching to the target position $(0.57 \mathrm{~m})$, the external disturbance is attacking the vessel in several times. At $3 \mathrm{~s}, 7 \mathrm{~s}$ and $11 \mathrm{~s}$, the vessel was attacked by pushing force toward harbour side. Conversely, at $14 \mathrm{~s}$ and $18 \mathrm{~s}$, pulling force attacked the vessel.

With the condition aforementioned, the vessel can approach to the final position in $14 \mathrm{~s}$ by controlling two actuators. The controlled vessel motion is illustrated in Fig. 6(a). Also, the rope tension and winch control signal are shown in Fig 6(b) and (c), respectively.

Fig. 6(d) shows the pressure change of damper cylinder during entire berthing process.

As shown in the experiment results, we can find out that the vessel is well controlled and robustly moves to the final position as intended, regardless of attacking of disturbance.

\section{CONCLUSION}

In the conventional berthing technologies or methods, there exist many limits to the safety of berthing operation where rudders, main propellers, thrusters, tugboats and mooring lines are generally provided. The high technologies have been developed and applied to many industry fields. However, the berthing work strongly still depends on human power and stays on the pre-modern technology level.

To overcome primitive berthing method, the authors proposed a new berthing technique/method by combining dampers and winches. The proposed idea was initialised by considering the real working conditions. As mentioned before, many working apparatuses for berthing should be prepared on land and on the sea side of harbours simultaneously. In this study, the authors proposed a new berthing method only using the apparatuses prepared 


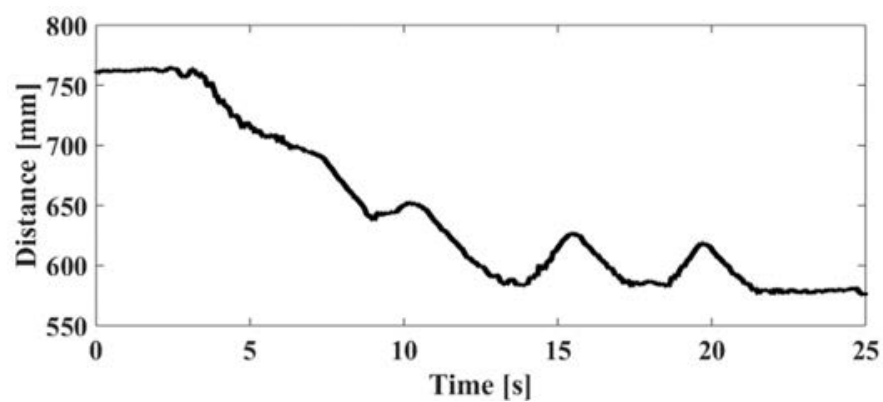

(a)

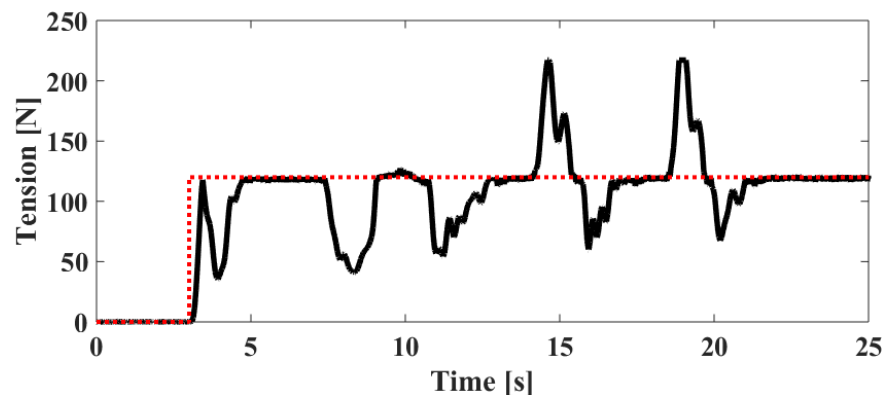

(b)

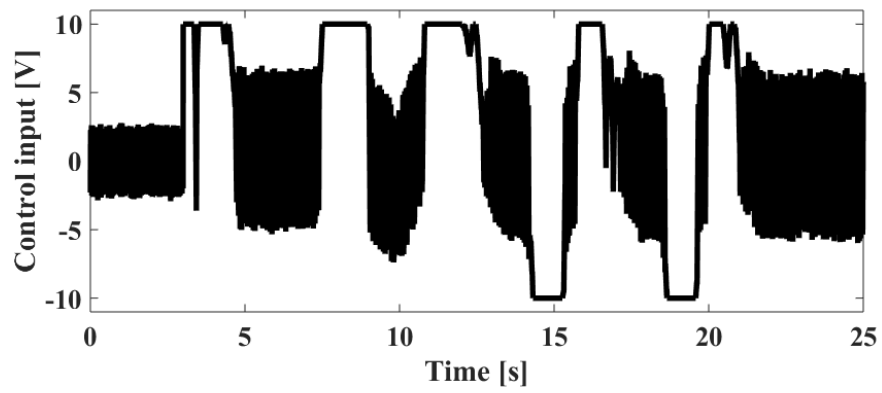

(c)

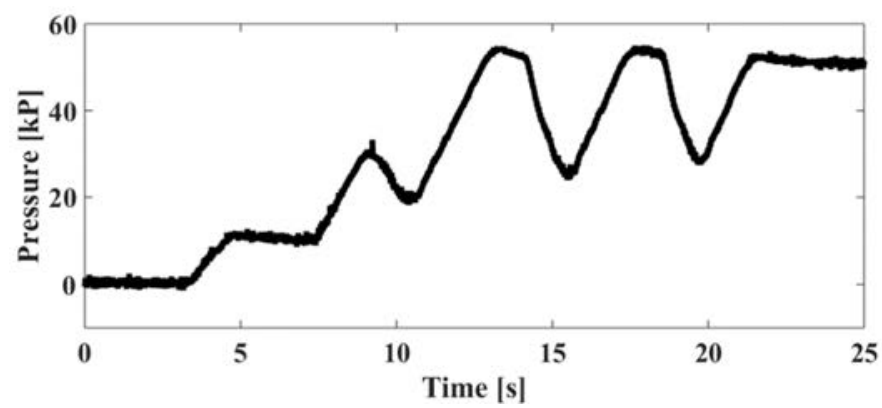

(d)

Figure 6: Experiment results. (a) Vessel position; (b) Winch rope tension; (c) Tension control input; and (d) Damper cylinder pressure. 
on land side without the sea side apparatuses. It is the novelty of this research such that we could obtain numerous advantages. The representative one is reduction of air pollution get from not using tugboats. Except that, it is expected that we find out uncountable side effects by providing the proposed technique.

\section{ACKNOWLEDGEMENTS}

This research was a part of the project titled 'Development of technology to commercialize flatfish automatic grader', funded by the Ministry of Oceans and Fisheries, Korea. This research was also part of the project titled 'Development of the ICT convergence smart sliding docking system', funded by the Ministry of SMEs and Startups, Korea.

\section{REFERENCES}

[1] Kim, K.H., Kim, B.G. \& Kim, Y.B., A study on the optimal tracking control system design for automatic ship berthing. Journal of the Korean Society for Power System Engineering, 22(4), pp. 72-80, 2018. DOI: 10.9726/kspse.2018.22.4.072.

[2] Kim, Y.B., Choi, Y.W. \& Chae, G.H., A study on the development of automatic ship berthing system. Proceedings of the Korean Society for Power System Engineering Autumn Conference, pp. 419-423, 2006.

[3] Kim. Y.B., Choi, Y.W., Suh, J.H. \& Lee, K.S., A study on the development of the realtime detection technique for automatic ship berthing. Proceedings of the Korean Society for Power System Engineering Spring Conference, pp. 306-313, 2006.

[4] Zhang, Y., Hearn, G.E. \& Sen, P., A multivariable neural controller for automatic ship berthing. IEEE Control Systems, 17(2), pp. 31-45, 1997.

[5] Bui, V.P., Jeong, J.H., Kim, Y.B. \& Kim, D.W., optimal control design for automatic ship berthing by using bow and stern thrusters. Journal of Ocean Engineering and Technology, 24(2), pp. 10-17, 2010.

[6] Bui, V.P., Kawai, H., Kim, Y.B. \& Lee, K.S., A ship berthing system design with four tug boats. Journal of Mechanical Science and Technology, 25(5), pp. 1257-1264, 2011. DOI: $10.1007 / \mathrm{s} 12206-011-0215-4$.

[7] Bui, V.P. \& Kim, Y.B., Development of constrained control allocation for ship berthing by using autonomous tugboats. International Journal of Control Automation and Systems, 9(6), pp. 1203-1208, 2011. DOI: 10.1007/s12555-011-0622-4.

[8] Hasegawa, K. \& Fukutomi, T., On harbour maneuvering and neural control system for berthing with tug operation. Proceedings of the International Conference Maneuvering and Control of Marine Craft, pp. 197-210, 1994. 